Finance and Economics Discussion Series Divisions of Research \& Statistics and Monetary Affairs Federal Reserve Board, Washington, D.C.

Imperfect Monitoring and the Discounting of Inside Money

David C. Mills, Jr.

2007-58

NOTE: Staff working papers in the Finance and Economics Discussion Series (FEDS) are preliminary materials circulated to stimulate discussion and critical comment. The analysis and conclusions set forth are those of the authors and do not indicate concurrence by other members of the research staff or the Board of Governors. References in publications to the Finance and Economics Discussion Series (other than acknowledgement) should be cleared with the author(s) to protect the tentative character of these papers. 


\title{
Imperfect Monitoring and the Discounting of
}

\author{
Inside Money
}

\author{
David C. Mills, Jr. ${ }^{1}$ \\ Federal Reserve Board of Governors
}

May 24, 2007

\begin{abstract}
${ }^{1}$ Correspondence: Federal Reserve Board of Governors, Mail Stop 188, 20th \& C Streets, NW, Washington, DC 20551. Email: david.c.mills@frb.gov. Office: 202-530-6265. Fax: 202-872-7533. The author thanks Travis Nesmith, Geoff Gerdes, Will Roberds and seminar participants at Texas A\&M University, Iowa State University, the 2006 Winter Meetings of the Econometric Society in Boston, the Midwest Macroeconomics Meetings at Washington University, the Federal Reserve Bank of Cleveland's Workshop on Money, Banking and Payments, and the Midwest Economic Theory Meetings at Vanderbilt University for comments and suggestions and the research assistance of Daniel Dube and Adam Doverspike. The views in this paper are solely the responsibility of the author and should not be interpreted as reflecting the views of the Board of Governors of the Federal Reserve System or of any other person associated with the Federal Reserve System. All errors are the responsibility of the author.
\end{abstract}




\begin{abstract}
One of the fundamental questions concerning inside money is whether its issuers should be regulated and how. This paper evaluates the efficiency of one prevalent regulatory recommendation - a requirement that private issuers redeem inside money on demand at par - in a random-matching model of money where the issuers of inside money are only imperfectly monitored. I find that for sufficiently imperfect monitoring, a par redemption requirement leads to lower social welfare than if private money were redeemed at a discount. A central message of the paper is that if inside money and outside money are not perfect substitutes for one another, as is the case if there is sufficiently imperfect monitoring, a par redemption requirement may not be socially optimal because such a requirement effectively binds them to circulate as if they are. Such an outcome is a version of Gresham's law that bad money drives out good money.

Keywords: Inside and outside money, electronic money, imperfect monitoring, Gresham's law

JEL Classification: E40, E42.
\end{abstract}




\section{Introduction}

The emergence of electronic money such as stored-value and prepaid cards has renewed interest in inside (or private) money schemes. Two fundamental questions concerning inside money is whether its issuers should be regulated and how. Nineteenth century arguments, as well as more recent debates between free-banking advocates and monetarists, focus on two extremes. At one extreme is the banking school, which advocated for a relatively laizzefaire approach to private note issue. At the other extreme is the currency school, which advocated for a public monopoly on money with strict controls. More recently, the relaxation of legal restrictions on the issuance of inside money means that modern debates focus on the degree of regulation to which private issuers may be subject. This paper evaluates the efficiency of one prevalent regulatory recommendation - a requirement that private issuers redeem inside money on demand at par - in a model where inside and outside money coexist, and the issuers of inside money are imperfectly monitored. I find that for sufficiently imperfect monitoring of inside money issuers, a par redemption requirement leads to lower social welfare than if private money were redeemed at a discount.

The par redemption requirement seems common throughout recent mon- 
etary history. Such a requirement existed in most free-banking states during the Free Banking Era (1838-60) in the United States. ${ }^{1}$ More recently, the European Central Bank (1998) has established a policy on electronic money for the Eurosystem that stipulates several minimum requirements of electronic money issuers, including par redemption. ${ }^{2}$ Motivations for such a requirement include the safety and efficiency of the payment system. The safety argument is that par-redemption restricts the ability of inside money issuers to overissue, making an inside money scheme feasible. The efficiency argument is that currencies trading at varying exchange rates diminishes the unit-of-account function of money and so is inefficient. Implicit in this argument is the belief that inside and outside money should effectively circulate as a uniform currency, i.e. they are essentially perfect substitutes. Thus, it seems natural to ask : 1) In what settings are inside money schemes feasible? 2) In what settings are inside money and outside money not perfect substitutes? and 3) Are there any welfare implications in these settings from a par redemption requirement?

Recent research in monetary theory has shed some light on the first two questions. Cavalcanti-Wallace (1999b) provide a random-matching model of inside money (with no outside money) that is feasible because of society's 
ability to perfectly monitor the trading histories of the issuers. ${ }^{3}$ This is because monitoring enables agents to punish and reward the issuers in the future for current actions. If the long-term rewards of consistent issue and redemption exceed the short-term benefits of overissuing, inside money issuers have an incentive not to overissue. In another paper, Cavalcanti-Wallace (1999a) go on to say that in an environment in which society can perfectly monitor inside money issuers, inside money is a perfect substitute for outside money, but not vice versa. Inside money can duplicate any allocation that is achievable with outside money and can also achieve even more desirable allocations because it gives private issuers access to instant liquidity which can increase trading. In such an environment, outside money is inessential, so if both types of money were to circulate, it seems optimal that they do so as a uniform currency, and a par-redemption requirement would be innocuous.

Mills (2006) generalizes the basic model in Cavalcanti-Wallace (1999a,b) by allowing (i) both inside and outside money to circulate, and (ii) monitoring of issuers to be imperfect, and overturns their result in CavalcantiWallace (1999a) by showing that both inside and outside money are necessary to implement certain allocations. Such a result suggests that inside and outside money are not perfect substitutes for one another in the case of 
imperfect monitoring. While inside money retains the advantage it has in Cavalcanti-Wallace (1999a), imperfect monitoring implies that issuers have greater incentive to overissue, restricting its value. Outside money is not subject to such constraints and so can trade for higher levels of output. Due to the complexity of the general problem, Mills (2006) does not attempt to characterize the relative welfare of alternative monetary schemes.

The current paper, a simplified version of that in Mills (2006), provides some insight on the third question mentioned above. The model is a randommatching model of money in which some people (bankers) can be publicly monitored via a record-keeping technology while others (nonbankers) cannot be monitored at all because their trading histories are private information. I model imperfect monitoring of inside money issuers (bankers) via a lag in the record-keeping technology's updating of banker trading histories. I present numerical examples of implementable allocations for various updating lags. For lags that are neither too small nor too large, I find optimal allocations where inside money is redeemed by its issuers at a discount relative to outside money in the following sense: inside money issuers produce more to obtain outside money than they do to redeem inside money. The results are numerical because, as shown in Mills (2006), the updating lag of banker histories 
must be neither too short nor too long for the coexistence of both types of assets to be essential.

The results suggest that a par redemption requirement reduces welfare because it reduces the value of outside money. This intuition is straightfoward. The par requirement cannot raise the value of inside money in an environment with sufficiently imperfect monitoring because doing so would provide an incentive to overissue in the sense that inside money issuers do not wish to redeem notes. Thus, the only way to satisfy the par redemption requirement is to make inside money a perfect substitute for outside money by undoing the advantage that outside money has over inside money - namely that it can trade for higher levels of output. Such an outcome is a version of Gresham's law that bad money drives out good.

The connection between imperfect monitoring and the ability to issue inside money goes back at least to Klein (1974), who stresses the importance of reputations for private bankers to issue inside money, although in a model quite different from the one here ${ }^{4}$. King (1983) argues that imperfect information and monitoring are central to understanding inside money. Nonetheless, recent work on the coexistence of outside and inside money by Williamson (1999), Azariadis-Bullard-Smith (2001), Bullard-Smith (2000) 
and Marimon-Nicolini-Teles (2003) has not focused on the challenge that imperfect history and monitoring present to the circulation of inside money. Indeed, each of these works model inside money in such a way that inside and outside money should effectively be perfect substitutes for one another. This is a direct artifact of their abstraction from imperfect monitoring.

The rest of the paper is organized as follows. Section 2 presents the environment. Section 3 describes the restricted class of mechanisms I study and the conditions for implementability. Section 4 presents the main example and results, while section 5 offers concluding remarks.

\section{The Economic Environment}

The background environment is the random-matching model of money from Shi (1995) and Trejos-Wright (1995). Time is discrete and the horizon is infinite. There are $S$ distinct, divisible, and perishable types of goods at each date and there is a $[0,1]$ continuum of each of $S$ specialization types of agents, where $S>2$. An agent whose specialization type is $s$ consumes only good $s$ and produces only good $s+1(\operatorname{modulo} S)$, for $s=1,2, \ldots, S$. Each agent maximizes expected discounted utility with a discount factor $\beta \in(0,1)$. 
Utility in a period is given by $u(c)-y$ where $c$ is the amount consumed and $y$ is the amount produced. The function $u$ is defined on $[0, \infty)$, is increasing, twice differentiable, and satisfies $u(0)=0, u^{\prime}>0, u^{\prime \prime}<0$, and $u^{\prime}(0)=\infty$. Moreover, there exists $y^{\max }>0$ such that $u\left(y^{\max }\right)=y^{\max }$.

Agents cannot commit to future actions. This implies that those agents who produce must expect to receive something of value for doing so.

The society is able to keep a public record of the actions of a fraction $B$ of each specialization type of agent, where $B \in[0,1]$. Agents whose histories are a part of the public record are called bankers. The fact that banker histories are part of a public record implies that it is possible for agents to monitor their behavior. As we shall see, this implies that bankers do not need to receive something tangible to induce them to produce in a singlecoincidence meeting; bankers can be rewarded and punished in the future for actions they take currently. Society has no public record for the remaining fraction $1-B$ of each specialization type, the nonbankers. The fact that nonbankers are anonymous implies that the society cannot monitor their behavior. The implication is that nonbankers must receive something tangible in order to produce. We can think of $B$ as society's capacity for keeping track of individual trading histories. 
Public information about banker histories is not perfect because the public record is not updated immediately after every action. Specifically, there is a deterministic lag of $T$ periods, where $T \geq 0$. At the beginning of each date $t>T$, the bankers' trading histories are known up through what they did until the beginning of date $t-T$. For $t \leq T$, banker histories are unknown. Thus, if $T=0$, then banker histories are completely publicly known and society can perfectly monitor their actions. If $T$ is sufficiently large, then banker histories are effectively unknown and society cannot monitor their actions at all. We can think of $T$ as society's ability to update records.

In each period, nonbankers are randomly matched in pairs with either other nonbankers or with bankers. For simplicity, it is assumed that bankers never meet each other. A single-coincidence meeting is a meeting that contains a type $s$ agent (the producer) and a type $s+1$ agent (the consumer) for some $s$. There are three basic types of single coincidence meetings: meetings between nonbankers, meetings in which a banker is a producer and a nonbanker is a consumer, and meetings in which a nonbanker is a producer and a banker is a consumer. A no-coincidence meeting is a meeting in which neither agent produces what the other consumes. Because $S>2$, there are no meetings in which there is a double-coincidence of wants. 
There are two distinct assets. These assets are indivisible and agents can carry at most one unit of one asset across dates. It is not possible for an agent to simultaneously hold a unit of both assets. Each banker has a technology that permits her to create distinct, indivisible and perfectly durable objects, called notes. Because these notes are a type of credit instrument that is issued by private individuals and may circulate as a means of payment, they may serve as inside money. The notes issued by a single banker are distinguishable from those issued by another so that counterfeiting is not a problem. Outside money, on the other hand, is neither produced nor consumed. It is indivisible and perfectly durable. Without loss of generality, refer to asset 1 as the inside money and asset 2 as the outside money.

When two agents meet, the following is common knowledge: each trading partner's specialization type, asset holdings, information type (banker or nonbanker) and the past actions of the bankers in the meeting that occurred up to $t-T$ periods ago. 


\section{Allocations}

I shall now describe the limited class of allocations. Allocations are both stationary and symmetric. Stationarity implies that there is a steady-state distribution of assets among agents. Symmetry implies two things. First, current actions are independent of an individual's specialization type and his relative position within that type. Second, notes issued by bankers are treated symmetrically by the agents in the economy. That is to say, nonbankers treat notes issued by each banker as perfect substitutes for those issued by every other banker, and bankers redeem each others' notes.

The symmetry restriction that all bankers' notes are treated identically may seem stark, but it is not without precedent in historical inside money systems. What I have in mind is a particularly efficient but unmodeled clearinghouse mechanism of which bankers are members. Under such a mechanism, the bankers agree to redeem each others' notes at par. The Suffolk bank in New England served as such a clearinghouse during the Free Banking Era. ${ }^{5}$ Regardless, the restriction that banknotes are perfect substitutes for each other makes it harder for me to show that a par-redemption requirement with outside money is inefficient because there is only one effective type of inside money to be redeemed at par. 
Trade takes place only in single-coincidence meetings in which there has been no discovered defection. The make-up of a single-coincidence meeting depends on four things: the information type and asset-holding of both the producer and consumer. Let the set of information types be $\{b, n\}$ where $b$ indicates that an agent is a banker and $n$ indicates that he is a nonbanker. I shall identify agent asset-holdings by states. Nonbankers are in one of three states in the set $A=\{0,1,2\}$. A nonbanker in state 0 has no asset-holdings. A nonbanker in state 1 has a unit of inside money and one in state 2 has a unit of outside money. Because of the symmetry imposed on banknotes, bankers do not gain from holding other bankers' notes and so never hold a note issued by another banker. They may, however, hold outside money. Thus, a banker is in one of two states, $\{1,2\}$. A banker in state 1 does not have a unit of outside money and a banker in state 2 does have a unit of outside money.

If trade takes place in a single-coincidence meeting, it involves the transfer of a level of output and money-holdings. If a banker chooses not to trade, then that banker is a defector. A nonbanker does not receive such a label because a defection by him would never be discovered. A defection by a banker is discovered $T$ periods from the date it occurred (say date $t$ ). For 
the $T-1$ periods that follow an initial defection, a banker is an undiscovered defector. An undiscovered defector can costlessly choose to either participate in trade or to defect again. From period $t+T$ on, a defecting banker is a discovered defector and is punished with autarky in all future meetings. ${ }^{6}$

There are at most 21 different single-coincidence meetings. Formally, let $m_{i j}^{k l}$ denote a single-coincidence meeting between a producer of information type $k$ in state $i$ and a consumer of information type $l$ in state $j$, where $i, j \in A$ and $k, l \in\{b, n\}$. I restrict the class of allocations further in several ways. First, I do not allow bankers to give gifts to nonbankers, even if the monitoring of bankers makes it incentive compatible for them to do so $\left(m_{10}^{b n}, m_{20}^{b n}, m_{22}^{b n}\right)$. This assumption is meant to capture that most transactions in an economy are not based on the giving of gifts. Second, I anticipate several meetings will have no trade because of various feasibility and incentive constraints $\left(m_{00}^{n n}, m_{10}^{n n}, m_{20}^{n n}, m_{11}^{n n}, m_{22}^{n n}, m_{11}^{n b}, m_{22}^{n b}\right)$. Third, I impose no trade in meetings where agents could trade assets $\left(m_{21}^{n n}, m_{12}^{n n}, m_{12}^{n b}, m_{21}^{n b}\right)$. AiyagariWallace-Wright (1996) has shown that the existence of two distinct assets may improve welfare in environments with the assumed indivisibility of assets and upper-bound on money-holdings because it increases the frequency of trades by allowing agents to exchange a higher-valued asset for a lower- 
valued asset and production. Thus, optimal allocations in such settings suggest that two monies should trade at different levels even when there is perfect monitoring. I do not want such an effect here because I do not want the benefit of inside money redeemed at a discount to be derived from it. ${ }^{7}$

There are four non-negative levels of output in single-coincidence meetings: $y_{1}^{n}, y_{2}^{n}, y_{1}^{b}$ and $y_{2}^{b}$. The output level $y_{1}^{n}$ is relevant in trades between nonbankers that involve inside money $\left(m_{01}^{n n}\right)$ whereas $y_{2}^{n}$ is relevant in trades between nonbankers that involve outside money $\left(m_{02}^{n n}\right)$. In both these types of meetings, the nonbankers switch states (the producer acquires the asset while the consumer surrenders it).

The output level $y_{1}^{b}$ is relevant in trades between nonbankers and bankers where inside money is either issued or redeemed $\left(m_{01}^{n b}, m_{11}^{b n}, m_{21}^{b n}\right)$. In meetings $m_{01}^{n b}$ inside money is issued (the nonbanker leaves the meeting in state 1 , as does the banker, who does not switch states). In meetings $m_{11}^{b n}$ and $m_{21}^{b n}$, inside money is redeemed (the nonbanker switches to state 0 while the banker does not change states). When bankers redeem notes, they destroy them. Bankers redeem notes issued by any banker.

By assuming that the level of output required when a note is issued is the same as the output required when a note is redeemed, I am assuming that 
banknotes do not bear "interest." While it may be optimal for these output levels to differ in a more general model, the fact that banknotes do not bear interest is consistent with historical episodes of inside money. Moreover, the symmetry of output for issue and redemption makes it harder to demonstrate that a par redemption requirement is inefficient.

Finally, the output level $y_{2}^{b}$ is relevant in trades between nonbankers and bankers that involve outside money $\left(m_{02}^{n b}, m_{12}^{b n}\right)$. In each of the meetings outside money changes hands so consumers and producers switch states. This also implies that inside money is never issued nor redeemed in such meetings. As was the case for inside money, it is assumed that the purchase or sale of goods for outside money is the same for meetings between bankers and nonbankers. This may not be optimal in a more general model, but is consistent with agents facing a uniform price for payment with outside money regardless of type. ${ }^{8}$ Like the restrictions for inside money, this restriction on outside money adds more symmetry, making it harder to demonstrate that a par redemption requirement is inefficient.

The relationship of primary interest is that between $y_{1}^{b}$ and $y_{2}^{b}$. If $y_{1}^{b}=$ $y_{2}^{b}$ then nonbanker consumers receive the same level of output from bankers whether they redeem inside money or trade outside money. Under this 
relationship, I say that inside money is redeemed at par. If $y_{1}^{b}<y_{2}^{b}$, then inside money is redeemed at a discount. Also of interest is the relationship between $y_{1}^{n}$ and $y_{2}^{n}$. If $y_{1}^{n}=y_{2}^{n}$ then inside money and outside money circulate at par, whereas if $y_{1}^{n}<y_{2}^{n}$ inside money circulates at a discount.

\subsection{Value Functions}

In this subsection, I describe the expected discounted utility for nonbankers, nondefecting bankers and undiscovered defecting bankers. These are all expressed given that no one else defects.

Let $x_{i}^{k}$ denote the fraction of each specialization type with information type $k$ in state $i$. Because each person must be in one of the states, the fractions of each specialization type in each state must satisfy

$$
\sum_{i \in A} x_{i}^{n}=1-B \text { and } \sum_{i=1}^{2} x_{i}^{b}=B
$$

Next, let $v_{i}^{k}$ denote the no-defection, expected discounted utility of an agent of information type $k$ who is in state $i$ at the start of a period. Suppose that everyone else follows the suggested outcome. The value functions for 
nonbankers can be written as:

$$
\begin{aligned}
v_{0}^{n}= & \beta v_{0}^{n}+\frac{x_{1}^{n}}{S}\left\{-y_{1}^{n}+\beta\left(v_{1}^{n}-v_{0}^{n}\right)\right\}+\frac{x_{1}^{b}}{S}\left\{-y_{1}^{b}+\beta\left(v_{1}^{n}-v_{0}^{n}\right)\right\} \\
& +\frac{x_{2}^{n}}{S}\left\{-y_{2}^{n}+\beta\left(v_{2}^{n}-v_{0}^{n}\right)\right\}+\frac{x_{2}^{b}}{S}\left\{-y_{2}^{b}+\beta\left(v_{2}^{n}-v_{0}^{n}\right)\right\} \\
v_{1}^{n}= & \beta v_{1}^{n}+\frac{x_{0}^{n}}{S}\left\{u\left(y_{1}^{n}\right)+\beta\left(v_{0}^{n}-v_{1}^{n}\right)\right\}+\frac{x_{1}^{b}+x_{2}^{b}}{S}\left\{u\left(y_{1}^{b}\right)+\beta\left(v_{0}^{n}-v_{1}^{n}\right)\right\} \\
v_{2}^{n}= & \beta v_{2}^{n}+\frac{x_{0}^{n}}{S}\left\{u\left(y_{2}^{n}\right)+\beta\left(v_{0}^{n}-v_{2}^{n}\right)\right\}+\frac{x_{1}^{b}}{S}\left\{u\left(y_{2}^{b}\right)+\beta\left(v_{0}^{n}-v_{2}^{n}\right)\right\}
\end{aligned}
$$

Consider (2). With probability $\frac{x_{1}^{n}}{S}$ the nonbanker is a producer in a singlecoincidence meeting with another nonbanker and acquires a banknote in exchange for production $y_{1}^{n}$. With probability $\frac{x_{1}^{b}}{S}$ the nonbanker is a producer in a single-coincidence meeting with a banker and acquires banknote in exchange for production $y_{1}^{b}$. With probability $\frac{x_{2}^{n}}{S}$ the nonbanker is a producer in a single-coincidence meeting with another nonbanker and acquires outside money in exchange for production $y_{2}^{n}$. With probability $\frac{x_{2}^{b}}{S}$ the nonbanker is a producer in a single-coincidence meeting with a banker and acquires outside money in exchange for production $y_{2}^{b}$. Equations (3) and (4) have similar interpretations for nonbankers with a unit of inside money and outside money respectively. 
The value functions for nondefecting bankers are:

$$
\begin{aligned}
v_{1}^{b}= & \beta v_{1}^{b}+\frac{x_{0}^{n}}{(1-B) S}\left\{u\left(y_{1}^{b}\right)\right\}+\frac{x_{1}^{n}}{(1-B) S}\left\{-y_{1}^{b}\right\} \\
& +\frac{x_{2}^{n}}{(1-B) S}\left\{-y_{2}^{b}+\beta\left(v_{2}^{b}-v_{1}^{b}\right)\right\} \\
v_{2}^{b}= & \beta v_{2}^{b}+\frac{x_{0}^{n}}{(1-B) S}\left\{u\left(y_{2}^{b}\right)+\beta\left(v_{1}^{b}-v_{2}^{b}\right)\right\}+\frac{x_{1}^{n}}{(1-B) S}\left\{-y_{1}^{b}\right\}
\end{aligned}
$$

For (5), with probability $\frac{x_{0}^{n}}{(1-B) S}$ a banker without a unit of outside money consumes $y_{1}^{b}$ and issues the nonbanker a new note. With probability $\frac{x_{1}^{n}}{(1-B) S}$ a banker without a unit of outside money produces $y_{1}^{b}$ and redeems a unit of inside money from the nonbanker. Finally, with probability $\frac{x_{2}^{n}}{(1-B) S}$ the banker produces $y_{2}^{b}$ and receives a unit of outside money. Equation (6) has a similar interpretation for bankers with a unit of outside money.

I calculate recursively the initial-defector expected discounted utility, given that no one else defects. The defecting banker's payoff must include the option of disagreeing to the suggested outcome in a meeting. It must also reflect the fact that she knows with certainty that her first defection will be discovered $T$ periods after it occurs and she will be punished with autarky from that date on. Let $\widetilde{v}_{i \tau}^{b}$ denote the expected discounted utility of a defecting banker who enters the period in state $i$ and who first defected $\tau$ 
periods ago. Then the value functions can be written as follows:

$$
\begin{aligned}
\widetilde{v}_{1 \tau}^{b}= & \beta \widetilde{v}_{1, \tau+1}^{b}+\frac{x_{0}^{n}}{(1-B) S}\left\{\max \left[u\left(y_{1}^{b}\right), 0\right]\right\}+\frac{x_{1}^{n}}{(1-B) S}\left\{\max \left[-y_{1}^{b}, 0\right]\right\} \\
& +\frac{x_{2}^{n}}{(1-B) S}\left\{\max \left[-y_{2}^{b}+\beta\left(\widetilde{v}_{2, \tau+1}^{b}-\widetilde{v}_{1, \tau+1}^{b}\right), 0\right]\right\} \\
\widetilde{v}_{2 \tau}^{b}= & \beta \widetilde{v}_{2, \tau+1}^{b}+\frac{x_{0}^{n}}{(1-B) S}\left\{\max \left[u\left(y_{2}^{b}\right)+\beta\left(\widetilde{v}_{1, \tau+1}^{b}-\widetilde{v}_{2, \tau+1}^{b}\right), 0\right]\right\} \\
& +\frac{x_{1}^{n}}{(1-B) S}\left\{\max \left[-y_{1}^{b}, 0\right]\right\}
\end{aligned}
$$

The difference between (5)-(6) and (7)-(8) is that $v_{h}^{b}$ is replaced with $\widetilde{v}_{h, \tau+1}^{b}$ and there are max terms associated with the fact that an undiscovered defecting banker will defect again when it is advantageous to do so. The presence of $\tau$ reflects the fact that the continuation payoff of a defecting banker is dependent on the time left before discovery. The terminal condition is

$$
\widetilde{v}_{i T}^{b}=0
$$

for $i=1,2$.

The expected discounted utility for a banker from an initial defection given that no one else defects, $\beta \widetilde{v}_{i 1}^{b}$, is what is relevant for the incentive constraints described below. This is obtained by solving $\widetilde{v}_{i \tau}^{b}$ recursively from the terminal condition $\widetilde{v}_{i T}^{b} \equiv 0$. The terminal condition incorporates the fact 
that once discovered, a defecting banker is punished with autarky forever.

\subsection{Constraints}

Now consider the constraints that are relevant for implementation. There are three sets of constraints: participation, free-disposal and steady-state. Participation constraints require that agents are ex-post sequentially rational. This is equivalent to the requirement that they receive non-negative gains from trade. The participation constraints can be summarized as follows:

$$
\begin{aligned}
y_{1}^{n} & \leq \beta\left(v_{1}^{n}-v_{0}^{n}\right) \\
y_{1}^{b} & \leq \beta \min \left[v_{1}^{n}-v_{0}^{n}, v_{1}^{b}-\widetilde{v}_{1,1}^{b}, v_{2}^{b}-\widetilde{v}_{2,1}^{b}\right] \\
y_{2}^{n} & \leq \beta\left(v_{2}^{n}-v_{0}^{n}\right) \\
y_{2}^{b} & \leq \beta \min \left[v_{2}^{n}-v_{0}^{n}, v_{2}^{b}-\widetilde{v}_{1,1}^{b}\right] \\
u\left(y_{1}^{n}\right) & \geq \beta\left(v_{1}^{n}-v_{0}^{n}\right) \\
u\left(y_{1}^{b}\right) & \geq \beta \max \left[v_{1}^{n}-v_{0}^{n}, \widetilde{v}_{1,1}^{b}-v_{1}^{b}\right] \\
u\left(y_{2}^{n}\right) & \geq \beta\left(v_{2}^{n}-v_{0}^{n}\right) \\
u\left(y_{2}^{b}\right) & \geq \beta \max \left[v_{2}^{n}-v_{0}^{n}, \widetilde{v}_{2,1}^{b}-v_{1}^{b}\right]
\end{aligned}
$$

Constraints (10)-(13) pertain to producers. For example, $y_{1}^{n}$ is produced 
in only one type of meeting, $m_{01}^{n n}$. If the producer agrees to trade he gets utility $-y_{1}^{n}+\beta v_{1}^{n}$, that is, the disutility of producing now plus the expected discounted utility of having a unit of inside money at the start of the next period. If the producer does not agree to trade, he is not discovered because he is a nonbanker, and enters next period with the expected discounted utility of a nonbanker without a unit of either money, $\beta v_{0}^{n}$. The producer agrees with the trade if constraint (10) is satisfied.

Consider constraint (11). Output level $y_{1}^{b}$ is produced in three types of meetings, $m_{01}^{n b}, m_{11}^{b n}, m_{21}^{b n}$. Thus, $y_{1}^{b}$ must be less than the minimum difference of the expected values of the producers in each of those meetings. In the first meeting, $m_{01}^{n b}$, the producer is a nonbanker without money and his decision is analogous to that in constraint (10). In the meeting $m_{11}^{b n}$, the producer is a banker without outside money. If she agrees she redeems a unit of inside money and receives $-y_{1}^{b}+\beta v_{1}^{b}$. If she disagrees, then she is an initial defector and receives utility $\beta \widetilde{v}_{1,1}^{b}$. The decision for a banker producer in a $m_{21}^{b n}$ meeting is analogous to that of a banker producer in $m_{11}^{b n}$, but the expected discounted utilities are for a banker with a unit of outside money.

Constraints (12) and (13) are also derived this way. In the case of (13), it should be noted that a banker producer who defects in a meeting $m_{12}^{b n}$ receives 
expected utility for a banker without a unit of outside money, $\beta \widetilde{v}_{1,1}^{b}$. If she accepts, then she receives a unit of outside money and has utility $-y_{2}^{b}+\beta v_{2}^{b}$. Constraints (14)-(17) are the participation constraints for consumers in each of the meetings and are derived in a way similar to that of the producer participation constraints.

Free-disposal constraints imply that nonbankers never dispose of either inside money or outside money and that bankers do not dispose of outside money. They are

$$
v_{i}^{k} \geq v_{0}^{k}, \widetilde{v}_{2 \tau}^{b} \geq \widetilde{v}_{1 \tau}^{b}
$$

for all $k \in\{b, n\}, i \in A, \tau \in\{1,2, \ldots, T-1\}$.

Finally, the steady-state constraints impose restrictions on state transitions. A steady-state distribution of agents over states requires that the fraction of bankers in each state and the fraction of nonbankers in each state be constant. This can be expressed by equating the inflow and outflow of each state for nonbankers and bankers. The nonbanker inflow-equal-outflow 
equations are

$$
\begin{aligned}
x_{0}^{n}\left[x_{1}^{b}+x_{2}^{b}\right] & =x_{1}^{n}\left[x_{1}^{b}+x_{2}^{b}\right]+x_{2}^{n} x_{1}^{b} \\
x_{1}^{n}\left[x_{1}^{b}+x_{2}^{b}\right] & =x_{0}^{n} x_{1}^{b} \\
x_{2}^{n} x_{1}^{b} & =x_{0}^{n} x_{2}^{b}
\end{aligned}
$$

For bankers, there is one inflow-equal-outflow equation which reduces to (21).

\subsection{Implementable and Optimal Allocations}

This section concludes with two definitions. The first definition summarizes the set of implementable allocations as those that satisfy both incentive and feasibility constraints.

Definition 1 An allocation $\left(y_{1}^{n}, y_{2}^{n}, y_{1}^{b}, y_{2}^{b}\right)$ is implementable if there exists $\left(x_{i}^{k}\right)$ for $k \in\{b, n\}$ and $i \in\{0,1,2\}$ that satisfies (1)-(21).

The second definition describes optimal allocations. These allocations are those that maximize a social welfare function subject to the constraint that they are implementable. The social welfare function is defined as the ex-ante utility of a representative agent. ${ }^{9}$ 
Definition 2 An allocation is optimal if it maximizes

$$
W=\sum_{i, k} x_{i}^{k} v_{i}^{k}
$$

subject to (1)-(21).

Absent incentive constraints (that is, absent constraints (10)-(18)), it is well-known and easy to verify that the optimal allocation is $y_{1}^{n}=y_{2}^{n}=$ $y_{1}^{b}=y_{2}^{b}=y^{*}$ where $y^{*}$ is the $\arg \max u(y)-y$, or the level of output that maximizes joint-surplus in each of the single-coincidence meetings. This optimum, where inside money is redeemed at par with outside money, is the benchmark allocation against which implementable allocations are compared.

\section{Examples}

I now provide numerical examples to demonstrate that in an environment with sufficiently imperfect monitoring, the optimal allocation has inside money redeemed at a discount relative to outside money. This suggests that in some environments, a par-redemption requirement is suboptimal. The need for numerical examples stems from the complexity of an updating lag that is neither too short nor too long. If the lag is long enough, it would be optimal 
for an economy to circulate only outside money.

The examples take as given the parameters: $\{S, B, \beta, u(c)\}$, which include the number of specialization types in the economy, the fraction of each specialization type that are bankers, the discount factor, and the specification of the period utility function. The numerical values of the parameters are:

$$
\{S, B, \beta, u(c)\}=\left\{3,0.1,0.95, c^{\frac{1}{2}}\right\}
$$

The choices of $S, B$, and $\beta$ are somewhat arbitrary. The only importance given to the number of specialization types is that there are enough to eliminate the possibility of a double-coincidence of wants in a meeting. The minimum number of specialization types that accomplishes this is $S=3$. The explicit utility function for the calculations is $u(c)=c^{\frac{1}{2}}$. Such a utility function has a very simple form that satisfies all of the assumptions made in Section 2. Note $u(c)=c^{\frac{1}{2}}$ implies that the solution to $\max u(y)-y$ is $y^{*}=0.25$.

In addition to the parameters above, the examples have the following distribution over states that satisfies (1) and (19)-(21):

$$
x_{0}^{n}=0.36, x_{1}^{n}=0.18, x_{2}^{n}=0.36, x_{1}^{b}=0.05, x_{2}^{b}=0.05
$$


I am now in a position to compare the optimal allocations for a variety of updating lags, $T$. I employ standard numerical optimization methods to find the allocation $\left(y_{1}^{n}, y_{2}^{n}, y_{1}^{b}, y_{2}^{b}\right)$ that solves the problem in Definition 2 .

Figure 1 shows the optimal allocations without a par requirement for a variety of updating lags. Notice that for $T=0$, the optimal allocation is $y_{1}^{n}=y_{2}^{n}=y_{1}^{b}=y_{2}^{b}=0.25$, which is also the optimal allocation absent the incentive constraints. In this case, monitoring of bankers is perfect and none of the banker-producer participation constraints bind. Indeed, the monitoring of bankers works well enough that, as in Cavalcanti-Wallace (1999a), outside money is inessential; social welfare would be maximized with inside money alone. Thus, with perfect monitoring and both monies circulating, the solution has both par redemption by bankers and par trading among nonbankers.

The unconstrained optimum is implementable until $T=7$. Before $T=7$, although monitoring is imperfect, it is not sufficiently imperfect to suggest an allocation where there is not par redemption. As in the case with perfect monitoring, none of the participation constraints bind. At $T=7$, however, it is no longer implementable for all banker-producers to redeem inside money for $y_{1}^{b}=y_{2}^{b}=0.25$. In fact for any given $T \geq 7$, the optimal allocation 
stipulates that $y_{1}^{b}<y_{2}^{b}$. A par redemption requirement would force $y_{1}^{b}=y_{2}^{b}$. The only way to do this is by reducing the amount of output that can be traded for outside money, essentially undoing the advantage that outside money has over inside money. It cannot raise the value of inside money because doing so would violate banker-producer participation constraints. Bankers would then have an incentive to overissue by issuing notes when convenient, but refusing to redeem notes. Such an outcome is a version of Gresham's law that bad money drives out good.

A par redemption requirement's impact on welfare, therefore, is either innocuous (for $T<7$ ) or harmful (for $T \geq 7$ ). Figure 2 documents this by comparing welfare results for the example both with and without the requirement under various updating lags. It is important to note that the larger the updating lag is, the greater is the negative impact of a par redemption requirement. Thus, in the context of the model, the optimal policy when both outside and inside money circulate is to not require par redemption. Of course, if the lag gets large enough, it may be no longer optimal for inside money to circulate at all. Indeed, in the limit, inside money would no longer be feasible because bankers would effectively be nonbankers; that is, their trading histories would be unknown. ${ }^{10}$ 
It is worth noting also, from Figure 1, that there are lags such that even though the optimum suggests nonpar redemption, par trading among nonbankers may still be optimal. In the set of examples, par trading at $y_{1}^{n}=y_{2}^{n}=0.25$ is sustainable until $T=19$. From that point on, imperfect monitoring is sufficient enough that the use of inside money actually starts to reduce the value of outside money in nonbanker trades. Thus, there is a lag sufficiently long enough such that inside money would no longer be desirable.

On peculiar observation from Figure 1 is that $y_{2}^{b}$ is non-monotonic with an inflection point at $T=38$. The reason for this is the impact $y_{2}^{b}$ has on discounted expected utilities of bankers in meetings $m_{12}^{b n}$. In such a meeting, a banker produces for a unit of outside money. For $T<38$, the optimal $y_{2}^{b}$ is such that the net gain to banker-producers in these meetings $\left(-y_{2}^{b}+\beta\left(v_{2}^{b}-v_{1}^{b}\right)\right)$ is negative. Such an allocation is feasible because of the punishment to defecting is strict enough. Defection leads to expected utility $\widetilde{v}_{1,1}^{b}<v_{1}^{b}{ }^{11} \quad$ Intuitively, the value to bankers of issuing their own notes is so high, that producing for outside money is not desirable to them. The optimal allocation must take this into account when determining the value of $y_{2}^{b}$.

The net loss to bankers, however, gets smaller as $T$ gets larger and even- 
tually becomes positive at $T=38$. The reason is that bankers do not get as much consumption from issuing inside money (because of tighter incentive constraints on the redemption of inside money) and so acquiring outside money becomes more attractive. Once the net gain to bankers for acquiring outside money is positive, the optimal $y_{2}^{b}$ begins to increase.

The results are robust to varying levels of $\beta$. The paths for each optimal level of output look like Figure 1. Higher levels of $\beta$ can sustain the unconstrained optimal level of output longer. For example, for $\beta=0.93$, par redemption is optimal up to $T=3$, while for $\beta=0.99$, par redemption is optimal for up to $T=59$. For $\beta \leq 0.92$, the optimal allocation has redemption at a discount for all $T>0$.

Finally, Figure 3 display trading and redemption ratios for various lags for $\beta=0.95$. The trading ratio is simply $y_{1}^{n} / y_{2}^{n}$ and the redemption ratio is $y_{1}^{b} / y_{2}^{b}$. It is worth noting from Figure 3 that for $\beta=0.95$ there are rather large drops in value for inside money quickly. Nonetheless, relatively small lags can lead to nonpar redemption with "reasonable" discounts that are around $2 \%$. Such discounts exist in a somewhat different context as average fees that are charged to merchants for credit and debit card transactions. 


\subsection{Discussion: Allowing Agents to Trade Assets}

One of the restrictions made on allocations is that agents could not trade assets and so there is no trade in the meetings $\left(m_{21}^{n n}, m_{12}^{n n}, m_{12}^{n b}, m_{21}^{n b}\right)$. However, for the meeting $m_{12}^{n b}$, one could imagine the nonbanker producer presenting the unit of inside money for redemption by the banker consumer. The banker consumer cannot redeem the inside money with goods production, but rather with outside money. This is a single coincidence meeting where the nonbanker could produce for the banker and may be willing to do so if holding a unit of outside money is more valuable than holding a unit of inside money. ${ }^{12}$ Let $y^{s}$ denote the amount of production in such a meeting. Thus, one may wish to interpret par redemption by bankers as swapping outside money to redeem inside money with $y^{s}=0$ whereas redemption at a discount would occur if $y^{s}>0$. Similarly, for the meeting $m_{12}^{n n}$ we could determine whether or not inside money trades at par. Let $y^{n s}$ denote output in such a meeting.

As stated earlier, the assumed indivisibility of assets and the upper-bound on money-holdings suggest that an optimal allocation when $T=0$ would have $y^{s}>0$ so it would never be optimal to have par redemption in this sense. ${ }^{13}$ It is worth noting, however, that for the parameters of the above example (with $\beta=0.95$ ) in a revised model that allows swaps in this type of meeting, 
$y^{s}=0.1459$ when $T=0$ and remains that way until $T=10$. At that point, $y^{s}$ begins to rise. One could interpret $y^{s}>0.1459$ for $T \geq 10$ as sufficiently large enough lags for which inside money is redeemed at a discount relative to its perfect monitoring level.

It is also true that $y^{n s}>0$ for $T=0$ and follows the same behavior as

$y^{s}$ for similar $T$. The optimal output levels $y_{1}^{n}, y_{2}^{n}, y_{1}^{b}, y_{2}^{b}$ are also adjusted in order to meet incentive feasibility requirements. Specifically, $y_{1}^{b}<y_{2}^{b}$ and $y_{1}^{n}<y_{2}^{n}$ for all levels of $T$ so that par redemption and par trading in the sense used in this paper are never optimal.

\section{Concluding Remarks}

This paper argues that a requirement that inside money be redeemed at par with outside money may be inefficient if there is sufficiently imperfect monitoring of the issuers of inside money. In such an environment, inside and outside money are not perfect substitutes and a par-requirement forces them to circulate as if they are. The inefficiency that results is a version of Gresham's law that bad money drives out good money; satisfaction of the par redemption requirement reduces the amount of output that can be 
traded for outside money rather than increasing the amount of output that can be traded for inside money.

The par-redemption requirement could be one contributing factor to the relatively low number of electronic money schemes. For the issuers of electronic money, the inability of the public to perfectly monitor them may make it difficult to establish enough credibility to make it profitable for them to redeem their money at par.

In deriving the results, I make use of the assumption that agents can only hold one unit of one asset at a time. I conjecture that this assumption is not crucial. This is because what makes both types of money essential is the trade-off between outside and inside money. This trade-off would still exist if the assumption about the unit upper bound on money-holdings were dropped. The issue and redemption of inside money would still be subject to the imperfect monitoring of bankers, implying that the value of inside money is less than that of outside money. Nonetheless, the issuance of inside money would still provide bankers with liquidity that permits them to consume more frequently.

The focus on optimal steady-state allocations potentially eliminates some advantages to par redemption. For example, suppose that $y_{2}^{b}$ is constant 
over time but $y_{1}^{b}$ can fluctuate depending on agents' speculations. This fluctuation may not be socially desirable and a par redemption requirement may improve welfare in certain situations. Take the example in the paper when $T=0$. There $y_{1}^{b}=y_{2}^{b}$ is socially optimal. If agents' speculations led to an equilibrium where $y_{1}^{b}<y_{2}^{b}$ even though banker incentive constraints permit $y_{1}^{b}=y_{2}^{b}$, a par redemption requirement may provide benefit. An important assumption in this case is that the speculation only affects $y_{1}^{b}$ and not $y_{2}^{b}$. Future work could explore what such environments look like.

I assume that banknotes are treated symmetrically and so serve as perfect substitutes for one another. Alternative specifications of the model could relax that assumption to investigate issues associated with competing currencies. This is direction for future work.

Finally, I model outside money as a fixed stock of objects and so abstract from any incentives for its overissue. Indeed, a government's ability to provide a sound money has been challenged by Hayek and others in the private versus public provision of money debate on the grounds that governments also have an incentive to overissue. Further, there is much work done in monetary economics in general regarding the government's incentive to overissue and how this incentive impacts a government's ability to provide 
sound money. This model is a useful starting point to add to these debates. Future work could incorporate a government in the model and introduce its objective and society's ability to monitor it and how these assumptions impact the incentive to overissue outside (or public) money.

\section{Notes}

${ }^{1}$ See, for example, Rolnick-Weber (1988).

${ }^{2}$ Issuers are permitted to charge a small fee only to recoup costs of carrying out such a transaction. In the model of this paper, these transactions costs are assumed to be zero.

${ }^{3}$ Indeed, solid and transparent legal arrangements, which define enforceable rights and obligations of participants is another regulatory requirement of electronic money schemes in the Eurosystem.

${ }^{4} \mathrm{His}$ model is one of competing issuers, while mine has a great deal of cooperation in the sense that issuers redeem others' notes.

${ }^{5}$ See Rolnick-Smith-Weber (1998) for a description of the Suffolk Banking System.

${ }^{6}$ The autarky punishment is the simplest form of punishment but is overly draconian. It is a sufficient punishment for the inside money scheme in the model to be incentive feasible but not necessary. See Wallace (2005) for a recent contribution on a weaker form of punishment where a discovered defecting banker joins the cohort of nonbankers, and so can continue to consume. Because weaker punishments have the effect of tighter banker incentive constraints, and it is the binding of incentive constraints that leads to the results 
of this paper, the qualitative results of this paper would go through with this weaker form of punishment.

${ }^{7}$ The results that follow generalize for allocations that allow for the trading of assets. The interpretation, however, is less intuitive. See the discussion following Section 4 .

${ }^{8}$ Mills (2006) provides a more general set-up of the problem which allows for unrestricted production levels in all possible single-coincidence meetings. An advantage of the more restrictive approach here is that it is much more tractable for welfare analysis.

${ }^{9}$ An alternative view could be to focus on the welfare of nonbankers subject to bankers receiving expected utility that is at least as large as that of the nonbankers. This has the benefit of interpreting nonbankers as households distinct from (and possibly owners of) the banking sector. In the results that follow, the banking sector is assumed to be quite small so that the social welfare defined here is drawn largely from the nonbankers and the interpretations would be similar under this alternative view of social welfare.

${ }^{10}$ See Mills (2006) for a discussion.

${ }^{11}$ One may be curious about the robustness of the impact of this on the par redemption requirement. Suppose the mechanism were restricted to allocations such that bankers must have nonnegative gains to acquiring outside money, $-y_{2}^{b}+\beta\left(v_{2}^{b}-v_{1}^{b}\right) \geq 0$. Such would be the case, for example, if bankers' transactions involving outside money were unobservable. This tighter constraint does bind when $T=0$ at the paper's optimal allocation of $y_{1}^{n}=y_{2}^{n}=y_{1}^{b}=y_{2}^{b}=0.25$ so that it is not the optimal allocation when both types of money circulate when $T=0$. There is a different optimal allocation in this setting such that $y_{2}^{b}>y_{1}^{b}$. In fact, this spread is crucial for feasibility. So the result that optimal allocations are those in which inside money is redeemed at a discount stands up to this 
weaker information structure.

${ }^{12}$ There are other meetings, particularly no-coincidence meetings, in which a banker could redeem a unit of inside money from a nonbanker by giving that nonbanker a unit of outside money. These could only occur at par, however, because there can be no utility from the consumption of goods. For the analysis that follows, I continue to rule out asset swaps in these types of meetings.

${ }^{13}$ Again, the reader is referred to Aiyagari-Wallace-Wright (1996) for a detailed explanation. 


\section{References}

[1] Aiyagari, S. R., N. Wallace, and R. Wright. 1996. "Coexistence of Money and Interest-bearing Securities." Journal of Monetary Economics, 37, $397-420$.

[2] Azariadis, C., J. Bullard and B. Smith. 2001. "Private and Public Circulating Liabilities." Journal of Economic Theory, 99, 59-116.

[3] Bullard, J. and B. Smith. 2003. "The Value of Inside and Outside Money." Journal of Monetary Economics, 50, 389-417.

[4] Cavalcanti, R. and N. Wallace. 1999. "Inside and Outside Money as Alternative Media of Exchange." Journal of Money, Credit and Banking, 31 Part 2, 443-57.

[5] Cavalcanti, R. and N. Wallace.1999. "A Model of Private Bank-Note Issue." Review of Economic Dynamics, 2, 104-136.

[6] European Central Bank. 1998. "Report on Electronic Money."

[7] King, R. 1983. "On the Economics of Private Money." Journal of Monetary Economics, 12, 127-158. 
[8] Klein, B. 1974. "The Competitive Supply of Money." Journal of Money, Credit, and Banking, 6, 423-454.

[9] Mills, D. 2006. "A Model in Which Outside and Inside Money are Essential." Macroeconomic Dynamics, forthcoming.

[10] Marimon, R., Nicolini, J., and Teles, P. 2003. "Inside-Outside Money Competition." Journal of Monetary Economics, 50, 1701-18.

[11] Rolnick, A., B. Smith and W. Weber. 1998. "Lessons from a LaissezFaire Payments System: The Suffolk Banking System (1825-58)." Federal Reserve Bank of St. Louis Review, 80, 105-16. Reprinted in the Federal Reserve Bank of Minneapolis Quarterly Review 22, 11-21.

[12] Rolnick, A. and W. Weber. 1988. "Explaining the Demand for Free Bank Notes." Journal of Monetary Economics, 21, 47-71.

[13] Shi, S. 1995. "Money and Prices: A Model of Search and Bargaining." Journal of Economic Theory, 67, 467-498.

[14] Trejos, A. and R. Wright. 1995. "Search, Bargaining, Money and Prices." Journal of Political Economy, 103, 118-141. 
[15] Wallace, N. 2005. "From Private Banking to Central Banking: Ingredients of a Welfare Analysis." International Economic Review, 46, 619-631.

[16] Williamson, S. 1999. "Private Money." Journal of Money, Credit, and Banking, 31 Part II, 469-491. 
Figure 1: Optimal Output Levels for Various Updating Lags

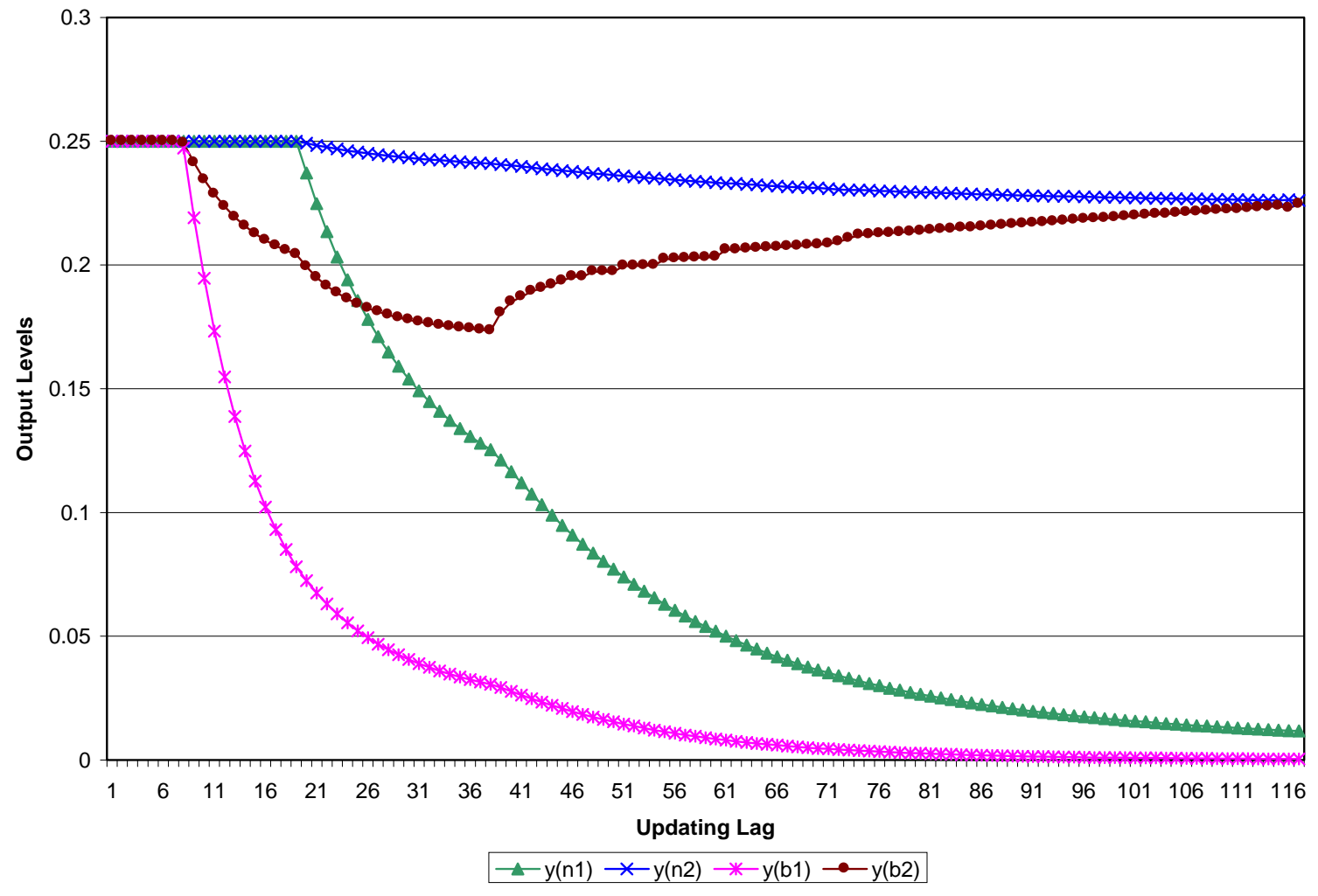


Figure 2: Social Welfare with and without Par Requirement

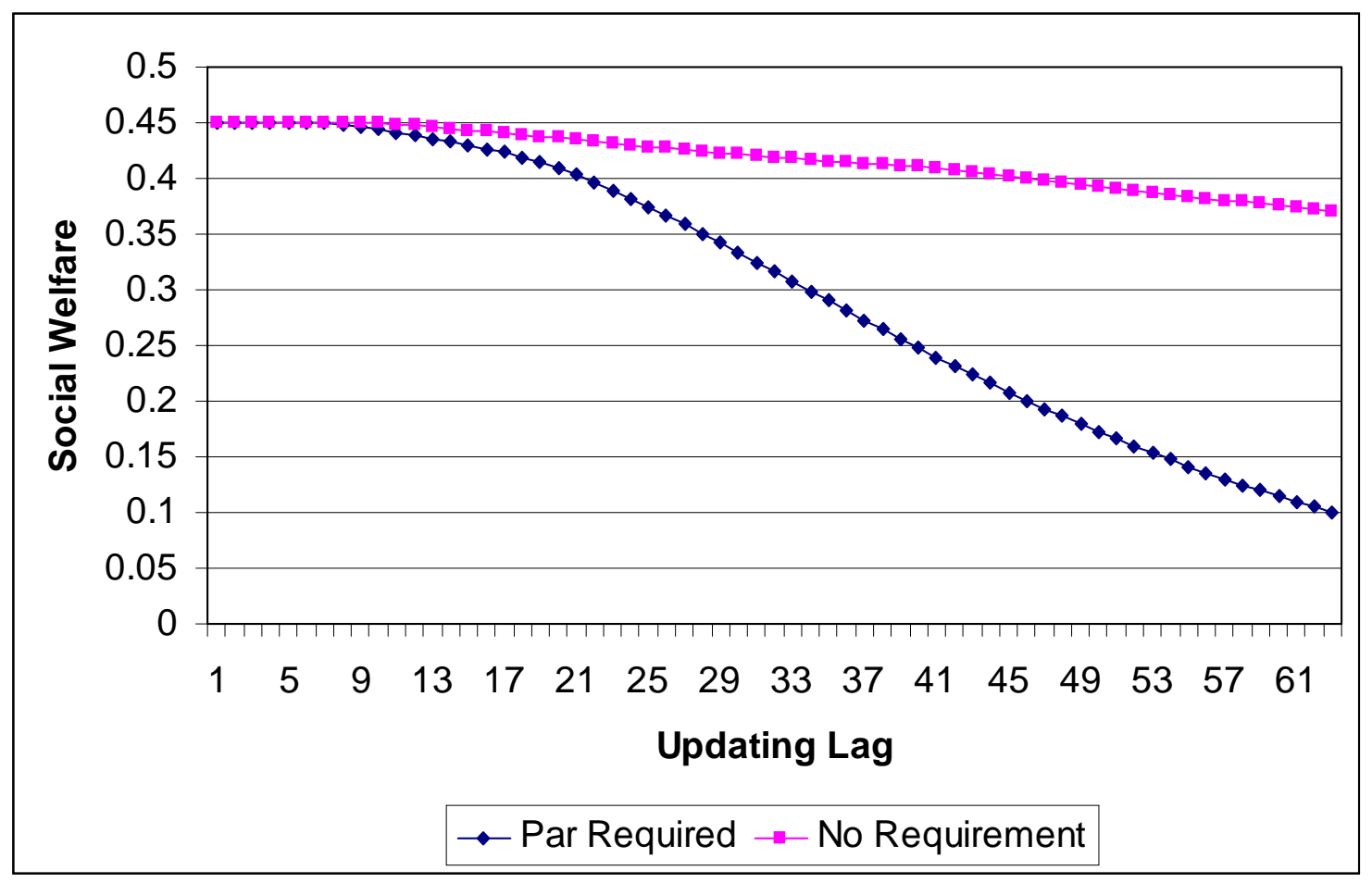


Figure 3: Redemption and Trading Ratios

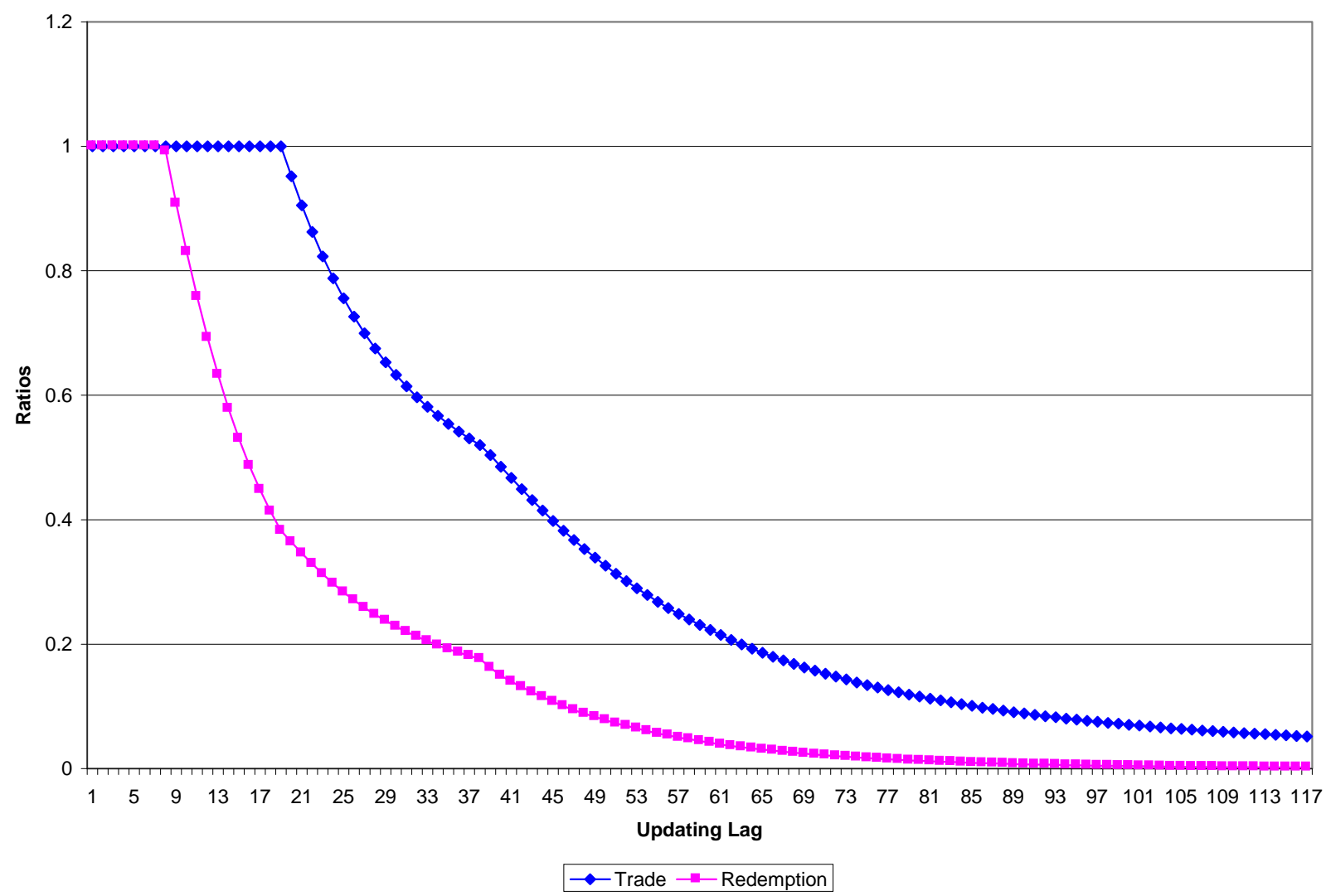

